\section{Clínica del hambre en la niñez}

\author{
Famine in children
}

El séptimo de los diez capítulos de la famosa monografía Maladie de Famine lleva el título "Clinique de la famine chez les enfants". Su autora fue la doctora A. Braude-Heller, médica en jefe del Hospital Bauman-Berson para niños de Varsovia, Polonia, con la colaboración de dos estudiantes de medicina. Maladie de Famine aparece en la renacida ciudad de Varsovia, en el temprano posbélico año de 1946. Quedando así cumplido el compromiso de sus autores: el de llevar a la luz pública el resultado de las "Investigaciones clínicas sobre el hambre, ejecutadas en el gueto de Varsovia en 1942", según reza el subtítulo de la obra.

Este esfuerzo colectivo, memorable paradigma imperecedero de heroicidad médica, surgió de la espontánea agrupación de médicos, químicos, biólogos, profesionales afines y estudiantes universitarios, encerrados en el gueto de Varsovia; o sea, víctimas a la vez ellos y sus familiares de la mayor hambruna antropogénica de los tiempos modernos, en perpetuo temor, además, de su "translocación" a los campos de exterminio, niños y adultos por igual. Les movía el afán vital, además del de intentar mitigar sufrimientos, de "investigar la naturaleza, epidemiología y evolución clínica del edema y la caquexia por inanición" para no rendirse ante la barbarie politizada. Para ellos así, intentando hacer caso omiso de su angustia inimaginable, su lacerante hambre física y la de sus seres queridos, saciar su hambre académica, la de saber más para beneficio de la Humanidad, la de tiempos menos horríficos, lo cual, como ya ha quedado dicho, desde luego exigía que los frutos de tal empresa llegasen al dominio público, si y cuando alguna vez recobrasen universal vigencia, verdad y sensatez.

Por fortuna, muy poco antes de la liquidación final (por obra del fuego) de aquel gigantesco gueto, casi toda la documentación quedó salvaguardada, gracias a la valerosa actuación de un profesor de la Universidad de Varsovia quien, a riesgo de su vida, recibió y custodió los principales frutos de aquellos escasos cinco meses de arduo trabajo clínico y de laboratorio, amén del tiempo requerido para la redacción de los futuros capítulos de la obra. Esto último, vale hacerlo notar, Ilevado al cabo en los sótanos de un cementerio, con las obligadas citas bibliográficas recobradas de la memoria individual de los autores.

Claramente, cada uno de los diez capítulos de Maladie de Famine difieren entre sí, en el estilo y formato. Es comprensible que la doctora Braude-Heller se viera precisada a presentar los resultados de su propia investigación en un estilo narrativo, atenido desde 
luego a los preceptos y formato propios de la literatura médica centroeuropea de aquellos tiempos. De tal modo, la oración inicial del capítulo, declara escuetamente: "Las primeras víctimas de la hambruna que ha recaído sobre nuestra comunidad judía durante la guerra, han sido los niños". Sin duda, ellos en infinita mayor medida de cómo lo han sufrido siempre los niños, ya sea los millones nacidos en condiciones de crónica inequidad social, de empobrecimiento agudo, de migraciones forzadas, sea cual fueren etnia, religión, filiación política o estamento de sus familias.

Así, por más motivos abyectos y circunstancias peores, durante las primeras etapas del conflicto bélico, entre los ingresos al hospital pediátrico dirigido por la doctora Braude-Heller, comenzaron a predominar niños lactantes, víctimas de la que pudiera haberse interpretado superficialmente como "patología de la pobreza", pero que a menudo evolucionaron en breve lapso a los estadios de gravedad entonces conocidos como "distrofia" y "atrofia". En esta etapa eran excepcionales los casos que exhibían edema; pero a medida que, por obvios motivos, se reducía la tasa de natalidad, y a raíz de la transformación del gueto de Varsovia en un gigantesco campo de concentración, dejaron de verse pequeños lactantes, los que se vieron sustituidos por pacientes de 2 a 15 años de edad, muchos de ellos con edema nutricional de creciente magnitud.

A principios del año 1942, todos los pacientes ingresados eran mayores de ocho años. Muchos niños previamente edematosos, ahora exhibían caquexia "seca", a consecuencia de la tristemente célebre ración diaria de cuando más 800 kilocalorías, carente de grasa, con una variable pero siempre mínima proporción de proteínas de origen vegetal.
A la par con el registro de esta secuencia en el tipo clínico de desnutrición, de clara naturaleza epidemiológica, los autores describen en detalle la evolución de las alteraciones psicológicas y en actitudes que aparecían precozmente y rápidamente evolucionaban a cuadros clínicos de clara índole psicótica.

Como también es propio de la evolución clínica, de lo que a raíz de la revolución conceptual nacida del genio de Federico Gómez Santos en el año 1946, se conoce como desnutrición de tercer grado, fue la dramática detención de crecimiento y desarrollo funcional de los pacientes. Llama la atención de los autores que en contraste con lo observado durante la guerra mundial de los años 1914-1918, no observaran casos de raquitismo carencial, mismo que indefectiblemente se halla condicionado por cierto crecimiento meta $-\mathrm{y}$ epifisario.

Explicablemente, la mayor parte del capítulo pediátrico se halla dedicado a las infecciones. Entre todas ellas sobresalía la tuberculosis. Abundan descripciones detalladas de casos insólitos de invasión multiorgánica y extremadamente graves de la enfermedad. La gran mayoría de ellos dieron respuesta negativa en la prueba de Mantoux. Incidentalmente, tampoco se observaba eosinofilia en los pacientes con parasitosis intestinales por nemátodos. La infecciones triviales como varicela y rubeola se expresaban por erupción insignificante y su contagiosidad era muy baja.

Resulta obligado hacer notar que algunos de los demás capítulos de Maladie de Famine también se refieren a investigaciones realizadas en niños, particularmente acerca de funciones metabólicas, algunas de ellas por primera vez. Así, la obra constituye una aportación científica fundamental para el entendimiento de la transitoriamente exitosa 
adaptación a la inanición; pero sin duda, reconozcamos que el enorme merito de las investigaciones allí reseñadas se achica ante la índole y magnitud de la proeza.

\section{LECTURAS RECOMENDADAS}

1. Apfelbaum-Kowalski E. (ed). Maladie de Famine. Recherches cliniques sur la famine exécutées dans le ghetto de Varsovia en 1942. Varsovia; American Joint Distribution Commitee. 1946.
2. Braude-Heller A, Rotbalsam J. Elbinger R. Clinique de 1 famine chez les enfants. En 1). P. 173-187.

3. Frenk S. Non omnis moriar. A cuarenta años de distancia de las investigaciones clínicas sobre el hambre realizadas en 1942 en el gueto de Varsovia. Gac. Méd. Méx. 1982;118: 509-511.

Dr. Silvestre Frenk Unidad de Genética de la Nutrición, Instituto de Investigaciones Biomédicas, UNAM

Instituto Nacional de Pediatría, SSA. sfrenk23@hotmail.com 